\title{
COTAS E DESEMPENHO ACADÊMICO: UMA ANÁLISE QUANTITATIVA SOBRE O CURSO DE PEDAGOGIA DA UFBA
}

\author{
QUOTA SYSTEM AND ACADEMIC PERFORMANCE: AN ANALYSIS \\ QUANTITATIVE ABOUT THE UFBA PEDAGOGY COURSE
}

\begin{abstract}
CUOTAS Y DESEMPEÑO ACADÉMICO: UN ANÁLISIS CUANTITATIVO SOBRE EL CURSO DE PEDAGOGÍA DE LA UFBA
\end{abstract}

Gabriel Swahili Sales de Almeida Universidade Federal da Bahia - Brasil

Caio Vinicius dos Santos Silva Universidade Federal da Bahia - Brasil

\begin{abstract}
Resumo: Este estudo busca investigar o perfil socioeconômico e o desempenho acadêmico dos estudantes cotistas e não-cotistas graduados entre os anos de 2005 e 2013 no curso de Pedagogia da Universidade Federal da Bahia (UFBA); totalizando um grupo de 194 licenciados. A pesquisa foi realizada com base no banco de dados da universidade, fornecido pela Pró-Reitoria de Ensino de Graduação (PROGRAD), que contempla todas as variáveis analisadas e, em especial, no aporte teórico de Delcele Queiroz (2001) e Lordêlo e Verhine (2001). As análises estatísticas foram realizadas no software IBM SPSS Statistics realizando testes nos indicadores de desempenho acadêmico. Como resultado, descobriu-se que o curso é composto expressivamente por discentes do sexo feminino, predominantemente jovens, pardas e pretas, oriundas da rede pública de ensino e com uma renda familiar mensal entre um e cinco salários mínimos. Ademais, verificou-se que, durante a graduação de Pedagogia, a Faculdade de Educação tem conseguido promover a equidade no desempenho das duas categorias estudantis. Os assistidos pela Política de Ações Afirmativas, ao final do curso superior, vencem as dessemelhanças de rendimento encontradas no vestibular, evidenciando, inclusive, um rendimento acadêmico maior do que os candidatos da ampla concorrência.
\end{abstract}

Palavras chave: Desempenho acadêmico. Sistema de cotas. UFBA.

\begin{abstract}
This study aims to investigate the socioeconomic profile and academic performance of quota students and non-quota students between 2005 and 2013 in the Pedagogy course of the Universidade Federal da Bahia (UFBA); totaling a group of 194 graduates. The research was carried out on the basis of the university database, provided by the Pró-Reitoria de Ensino de Graduação (PROGRAD), which covers all variables analyzed, and in particular, the theoretical contribution of Delcele Queiroz (2001) and Lordêlo and Verhine (2001). Statistical analyzes were performed in IBM SPSS Statistics software, performing tests on the academic performance indicators. As a result, it was found that the course is composed expressively by female students, predominantly young, brown and black, from the public school system and with a monthly family income between one and five
\end{abstract}


minimum wages. In addition, it was verified that during the graduation of Pedagogy, the Faculdade de Educação has managed to promote equity in the performance of the two student categories. Those assisted by the Affirmative Action Policy, at the end of the upper course, overcome the income dissimilarities found in the university entrance examination, evidencing, even, a higher academic achievement than the candidates of the wide competition.

Keywords: Academic achievement. Quota system. UFBA.

Resumen: Este estudio busca investigar el perfil socioeconómico y el desempeño académico de los estudiantes cuotistas y no-cuotistas graduados entre los años 2005 y 2013 en el curso de Pedagogía de la Universidade Federal da Bahia (UFBA); que totalizan un grupo de 194 licenciados. La investigación fue realizada sobre la base del banco de datos de la universidad, proporcionada por la Pró-Reitoria de Ensino de Graduação (PROGRAD), que contempla todas las variables analizadas y, en especial, en el aporte teórico de Delcele Queiroz (2001) y Lordêlo y Verhine (2001). Los análisis estadísticos fueran realizados en el software IBM SPSS Statistics realizando pruebas en los indicadores de desempeño académico. Como consecuencia, se descubrió que el curso está compuesto expresamente por estudiantes del sexo femenino, mayormente jóvenes, pardos y negros, oriundas de la red pública de enseñanza y con una renta familiar mensual entre uno y cinco salarios mínimos. Además, se verificó que, durante la graduación de Pedagogía, la Faculdade de Educação ha logrado promover la equidad en el desempeño de las dos categorías estudiantiles. Los beneficiarios de la Política de Acciones Afirmativas, al final del curso superior, vencen las desigualdades de rendimiento encontradas en el vestibular, evidenciando incluso un desempeño académico mayor que los candidatos de la amplia competencia.

Palabras clave: Desempeño académico. Sistema de cuotas. UFBA.

\section{INTRODUÇÃO}

Ingressar no ensino superior no Brasil, durante muitas décadas, foi privilégio das camadas dominantes. Somente os membros das famílias mais abastadas e, por vezes, raros alunos de outros segmentos sociais, considerados excepcionais, conseguiam acesso à universidade (DUBET, 2015). Consequentemente a origem e renda familiar constituíam-se como aspectos fundamentais de permissão para a entrada nos estabelecimentos de ensino superior brasileiros. Como evidenciam Santos e Almeida Filho (2008, p.226): “A universidade brasileira sempre foi uma instituição de formação das elites nacionais", nessa perspectiva, acreditava-se que os filhos das elites deveriam ocupar os espaços de formação intelectual para, em seguida, preencher os cargos de comando da União. Em contrapartida, os jovens das camadas populares eram designados a atividades servis e, quando tinham acesso aos estabelecimentos formais de educação, recebiam as instruções mais elementares como ler, escrever e contar. 
Neste cenário, por décadas, os movimentos sociais pleitearam ações afirmativas para a entrada de pessoas negras e pobres nas instituições de ensino superior (IES) públicas brasileiras. Considerando as desigualdades sócio-raciais no país, buscava-se, sobretudo, a equiparação de oportunidades para todos. Dessa maneira, forças sociais, como o Movimento Negro, pressionaram as autoridades institucionais em todo o país na tentativa de pluralizar o alunado das universidades.

No entanto, a democratização do acesso ao ensino superior público no Brasil foi efetivada apenas no início do século XXI, mais precisamente em 2003, quando as universidades estaduais do Rio de Janeiro (UERJ e UENF) implantaram regimes de reserva de vagas (DAFLON, et al., 2013) para os que foram classificados como estudantes carentes, entendidos como candidatos oriundos da rede pública de ensino, negros, e pessoas com deficiência. Em seguida várias outras IES, como a Universidade do Estado da Bahia - UNEB (2003), Universidade de Brasília - UnB (2004), e a Universidade Federal da Bahia - UFBA (2005), também adotaram a política de cotas.

No ano de 2012, através da Lei Federal 12.711, foi assegurada a reserva de 50\% (cinquenta por cento) das vagas das IES federais para egressos do ensino médio público, das quais $50 \%$ (cinquenta por cento) são destinadas a estudantes com renda familiar igual ou inferior a um salário mínimo e meio per capita. Esta lei também estabelece subcotas para candidatos pretos, pardos e indígenas em proporção equivalente à da população na unidade da Federação onde está instalada a instituição, tomando como referência o último censo da Fundação Instituto Brasileiro de Geografia e Estatística - IBGE. A partir de 2016, por meio da Lei $n^{\circ} 13.409$, este programa especial para o acesso às IES passou a contemplar uma reserva de vagas, neste mesmo regime, para pessoas com deficiência.

Diante disso, entendemos que analisar o perfil e desempenho acadêmico dos estudantes cotistas e não-cotistas de Pedagogia da UFBA é fundamental ampliar a compreensão sobre os efeitos da Política de Ações Afirmativas, implantada na UFBA em 2005 e legitimada pela União em 2012, na democratização do acesso ao ensino superior público brasileiro, bem como as implicações no rendimento estudantil deste novo grupo universitário. Busca-se descobrir se as instituições de ensino superior (IES) têm conseguido promover equidade nos desempenhos entre cotistas e não-cotistas. Para tanto, procurou-se conhecer os perfis dos estudantes de Pedagogia da UFBA; investigar o desempenho acadêmico dos estudantes cotistas e não-cotistas no referido curso; e contrastar, através de uma análise estatística, o desempenho dos dois grupos. 
Desse modo, entendendo o rendimento escolar como um indicador consistente de eficácia passível de ser auferido quantitativamente, a pesquisa pretende, por meio deste, fornecer informações aos gestores universitários e a comunidade em geral, contribuindo com a produção científica, a respeito da realidade no curso superior verificado. Além disso, esperase propiciar subsídios para a reelaboração ou ajustes nos programas em vigor e formulação de novas políticas na organização educacional.

\section{METODOLOGIA}

Esta averiguação se deu por meio de uma pesquisa documental, tendo como campo empírico a Universidade Federal da Bahia (UFBA), analisando especificamente o curso de Pedagogia e os sujeitos foram os estudantes graduados entre os anos de 2005 a 2013, totalizando um grupo de 194 licenciados. A pesquisa teve como subsídio o banco de dados da própria universidade, fornecido pela Pró-Reitoria de Ensino de Graduação (PROGRAD). As seguintes variáveis foram analisadas: sexo, faixa etária, cor ou raça, origem escolar, escolaridade dos pais, renda familiar, exercício de atividade remunerada durante o curso de graduação, acesso à internet, escore no vestibular (EscoreVest) e coeficiente de rendimento (CR).

No intuito de conhecer com maior propriedade as características do atual estudante de Pedagogia da UFBA, uma importante etapa desta pesquisa consistiu em analisar, a partir do banco de dados, as informações que compunham os perfis socioeconômicos destes alunos. Baseado nesses conhecimentos e nos estudos de Lordêlo e Verhine (2001) acerca do curso de Pedagogia da UFBA no final do século XX buscou-se elaborar uma comparação entre o novo perfil de aluno, no contexto da adoção à Política de Ações Afirmativas, e o perfil anterior. Assim, reconheceu-se, de forma mais nítida, o impacto que as cotas proporcionaram na configuração do alunado do curso de Pedagogia da UFBA.

Posteriormente realizou-se um estudo para investigar o desempenho dos estudantes cotistas e não-cotistas de Pedagogia no vestibular, forma de ingresso do aluno à UFBA no período estudado, bem como o coeficiente de rendimento dos alunos ao final do curso de graduação. Buscando perceber com maior propriedade as supostas diferenças entre o desempenho acadêmico dos estudantes tanto no vestibular quanto no coeficiente de rendimento, foi realizado, no software IBM SPSS Statistics, o Independent Samples Test. Para este Teste de Amostras Independentes foi utilizado o Levene's Test for Equality of Variances 
que possibilita verificar se as duas condições estudadas têm variâncias iguais a partir do pvalor.

As variáveis de desempenho acadêmico exploradas neste escrito também foram cruzadas à cor/raça do estudante, procurando averiguar possíveis relações. Além do recorte racial, a análise também cruzou as médias expostas nos processos de admissão e saída do ensino superior à modalidade de ingresso do aluno, cotista e não-cotista. Assim, almejou-se perceber as associações entre cor/raça, desempenho e cotas.

Por fim, para uma melhor interpretação de como os índices de desempenho se distribuem entre os dois grupos de estudantes, as variáveis EscoreVest e CR foram categorizadas em quintis. Neste modelo, as menores e maiores notas são encontradas no primeiro e último quintis, respectivamente. Subsequentemente efetuou-se a comparação entre o número de cotistas e não-cotistas em cada quintil. Dessa maneira foi possível observar, com base nas informações encontradas, se há equidade entre os estudantes cotistas e não-cotistas de Pedagogia.

\section{RESULTADOS E DISCUSSÕES}

Conforme as informações presentes no banco de dados da UFBA, no curso de Pedagogia há uma predominância de estudantes do sexo feminino $(93,3 \%)$ em relação ao masculino $(6,7 \%)$. Este resultado ratifica o que já havia sido observado por Delcele Queiroz (2001) e Lordêlo e Verhine (2001) que evidenciaram as mulheres em maior frequência no curso de Pedagogia da UFBA. A faixa etária prevalecente encontra-se nos discentes com 17 a 19 anos (38,7\%) acompanhados por acadêmicos de 20 a 22 anos (26,8\%), seguidos por alunos de 23 a 25 anos $(11,9 \%)$ e estudantes de 26 a 28 anos (9,3\%). Os universitários com 29 anos ou mais correspondem a 13,4\% do total. Em relação à origem étnico-racial estudantil, o curso é composto da seguinte forma: pardos $(50,3 \%)$, pretos $(36,7 \%)$, brancos $(10,1 \%)$, amarelos $(2,4 \%)$ e indígenas $(0,6 \%)$. Referente às cotas, o curso dispõe de $52 \%$ (92 estudantes) do corpo discente graduado de não-cotistas e $48 \%$ ( 85 estudantes) de cotistas. Todas as variáveis nesta pesquisa foram analisadas de acordo a estes dois grupos estudantis a fim de possibilitar um melhor contraste entre as categorias. 
Tabela 01: Características socioeconômicas dos graduados em Pedagogia na UFBA entre 2005 e $2013{ }^{1}$

\begin{tabular}{|c|c|c|c|}
\hline Variável & Cotista & Não-Cotista & Total \\
\hline \multicolumn{4}{|l|}{ Sexo } \\
\hline Feminino & $44,1 \%$ & $49,2 \%$ & $93,3 \%$ \\
\hline Masculino & $4,0 \%$ & $2,7 \%$ & $6,7 \%$ \\
\hline \multicolumn{4}{|l|}{ Idade } \\
\hline 17 a 19 anos & $10,2 \%$ & $27,7 \%$ & $37,9 \%$ \\
\hline 20 a 22 anos & $13,6 \%$ & $14,7 \%$ & $28,3 \%$ \\
\hline 23 a 25 anos & $9,0 \%$ & $2,3 \%$ & $11,3 \%$ \\
\hline 26 a 28 anos & $6,2 \%$ & $3,4 \%$ & $9,6 \%$ \\
\hline 29 a 31 anos & $1,1 \%$ & $1,1 \%$ & $2,2 \%$ \\
\hline 32 a 34 anos & $2,3 \%$ & $0,6 \%$ & $2,9 \%$ \\
\hline 35 a 37 anos & $2,3 \%$ & - & $2,3 \%$ \\
\hline 38 a 40 anos & $0,6 \%$ & $0,6 \%$ & $1,2 \%$ \\
\hline 41 anos ou mais & $2,9 \%$ & $1,7 \%$ & $4,6 \%$ \\
\hline \multicolumn{4}{|l|}{ Cor ou Raça } \\
\hline Amarelo & $1,3 \%$ & $1,3 \%$ & $2,6 \%$ \\
\hline Branco & $1,3 \%$ & $9,9 \%$ & $11,2 \%$ \\
\hline Indígena & $0,7 \%$ & - & $0,7 \%$ \\
\hline Pardo & $18,4 \%$ & $30,3 \%$ & $48,7 \%$ \\
\hline Preto & $23,7 \%$ & $13,2 \%$ & $36,9 \%$ \\
\hline \multicolumn{4}{|l|}{ Tipo de Escola E.M. } \\
\hline Escola Particular & - & $33,5 \%$ & $33,5 \%$ \\
\hline Escola Pública & $45,2 \%$ & $21,3 \%$ & $66,5 \%$ \\
\hline \multicolumn{4}{|l|}{ Instrução da Mãe } \\
\hline Nunca frequentou a escola & $1,3 \%$ & $0,6 \%$ & $1,9 \%$ \\
\hline Fundamental I Incompleto & $4,5 \%$ & $4,5 \%$ & $9,0 \%$ \\
\hline Fundamental I Completo & $5,2 \%$ & $2,6 \%$ & $7,8 \%$ \\
\hline Fundamental II Incompleto & $9,0 \%$ & $1,9 \%$ & $10,9 \%$ \\
\hline Fundamental II Completo & $3,2 \%$ & $1,9 \%$ & $5,1 \%$ \\
\hline Médio Incompleto & $5,8 \%$ & $1,3 \%$ & $7,1 \%$ \\
\hline Médio Completo & $12,9 \%$ & $25,8 \%$ & $38,7 \%$ \\
\hline Superior Incompleto & $0,6 \%$ & $5,2 \%$ & $5,8 \%$ \\
\hline Superior Completo & $1,9 \%$ & $10,3 \%$ & $12,2 \%$ \\
\hline Não sabe & $0,6 \%$ & $0,6 \%$ & $1,2 \%$ \\
\hline \multicolumn{4}{|l|}{ Instrução do Pai } \\
\hline Nunca frequentou a escola & $1,3 \%$ & - & $1,3 \%$ \\
\hline Fundamental I Incompleto & $6,5 \%$ & $2,6 \%$ & $9,1 \%$ \\
\hline Fundamental I Completo & $7,1 \%$ & $3,9 \%$ & $11,0 \%$ \\
\hline Fundamental II Incompleto & $8,4 \%$ & $4,5 \%$ & $12,9 \%$ \\
\hline Fundamental II Completo & $5,2 \%$ & $2,6 \%$ & $7,8 \%$ \\
\hline Médio Incompleto & $5,2 \%$ & $1,9 \%$ & $7,1 \%$ \\
\hline Médio Completo & $9,7 \%$ & $22,6 \%$ & $32,3 \%$ \\
\hline Superior Incompleto & $0,6 \%$ & $2,6 \%$ & $3,2 \%$ \\
\hline Superior Completo & - & $12,3 \%$ & $12,3 \%$ \\
\hline Não sabe & $1,3 \%$ & $1,9 \%$ & $3,2 \%$ \\
\hline \multicolumn{4}{|l|}{ Renda Familiar } \\
\hline Até $1 \mathrm{SM}$ & $4,5 \%$ & $1,9 \%$ & $6,4 \%$ \\
\hline Maior que 1 até $3 \mathrm{SM}$ & $25,0 \%$ & $16,0 \%$ & $41,0 \%$ \\
\hline Maior que 3 até $5 \mathrm{SM}$ & $12,2 \%$ & $17,9 \%$ & $30,1 \%$ \\
\hline
\end{tabular}

${ }^{1}$ Algumas somas não chegam a $100 \%$ devido à ausência de informações dos estudantes em determinadas variáveis. 


\begin{tabular}{lccc}
\hline Maior que 5 até 10 SM & $3,8 \%$ & $12,8 \%$ & $16,6 \%$ \\
Maior que 10 até 20 SM & - & $3,8 \%$ & $3,8 \%$ \\
Maior que 20 até 40 SM & - & $1,3 \%$ & $1,3 \%$ \\
Maior que 40 SM & - & $0,6 \%$ & $0,6 \%$ \\
Atividade Remunerada & & & \\
Exerceu & $20,0 \%$ & $12,7 \%$ & $32,7 \%$ \\
Não Exerceu & $24,7 \%$ & $42,7 \%$ & $67,4 \%$ \\
Acesso à internet & & & \\
Tem & $20,6 \%$ & $38,7 \%$ & $59,3 \%$ \\
Não Tem & $24,5 \%$ & $16,1 \%$ & $40,6 \%$ \\
\hline
\end{tabular}

Fonte: Elaborado pelos autores a partir dos dados da UFBA.

Com base nos dados coletados podemos realizar análises iniciais a respeito do perfil dos estudantes. É possível afirmar que Pedagogia é um curso com público expressivamente negro, visto que $85,6 \%$ do seu corpo discente é integrado por pretos ou pardos. Conforme destaca Santos (2009, p. 67-68):

[...] a presença de um maior contingente de estudantes negros [...] tem trazido efeitos ao universo acadêmico. Tais efeitos podem apresentar implicações no que concerne à permanência na universidade; às suas ambiências; à qualidade das interações entre os grupos (estudantesestudantes; estudantes-professores; estudantes-funcionários) e possibilidades de novas convergências ou conflitos ora mais, ora menos definidos em termos de classe e raça.

Em 2001, Delcele Queiroz observou que em Pedagogia havia uma frequência superior de estudantes pretos $(35,1 \%)$ na composição do alunado, enquanto os brancos $(15,3 \%)$ apresentavam-se, numericamente, em menor proporção. Os resultados atuais expõem que no curso investigado há 3,3 vezes mais pretos do que brancos. ${ }^{2} \mathrm{O}$ grupo dos não-cotistas revela um índice maior de alunos pardos $(30,3 \%)$ enquanto o dos cotistas apresentam maiores taxas de pretos $(23,7 \%)$.

\footnotetext{
${ }^{2}$ Neste momento as categorias comparadas foram "branco" e "preto" devido à compatibilidade aos estudos de Delcele Queiroz (2001) que classificou os estudantes em: brancos, morenos, mulatos e pretos.
} 
Gráfico 01: Relação Cor ou Raça x Cotas.

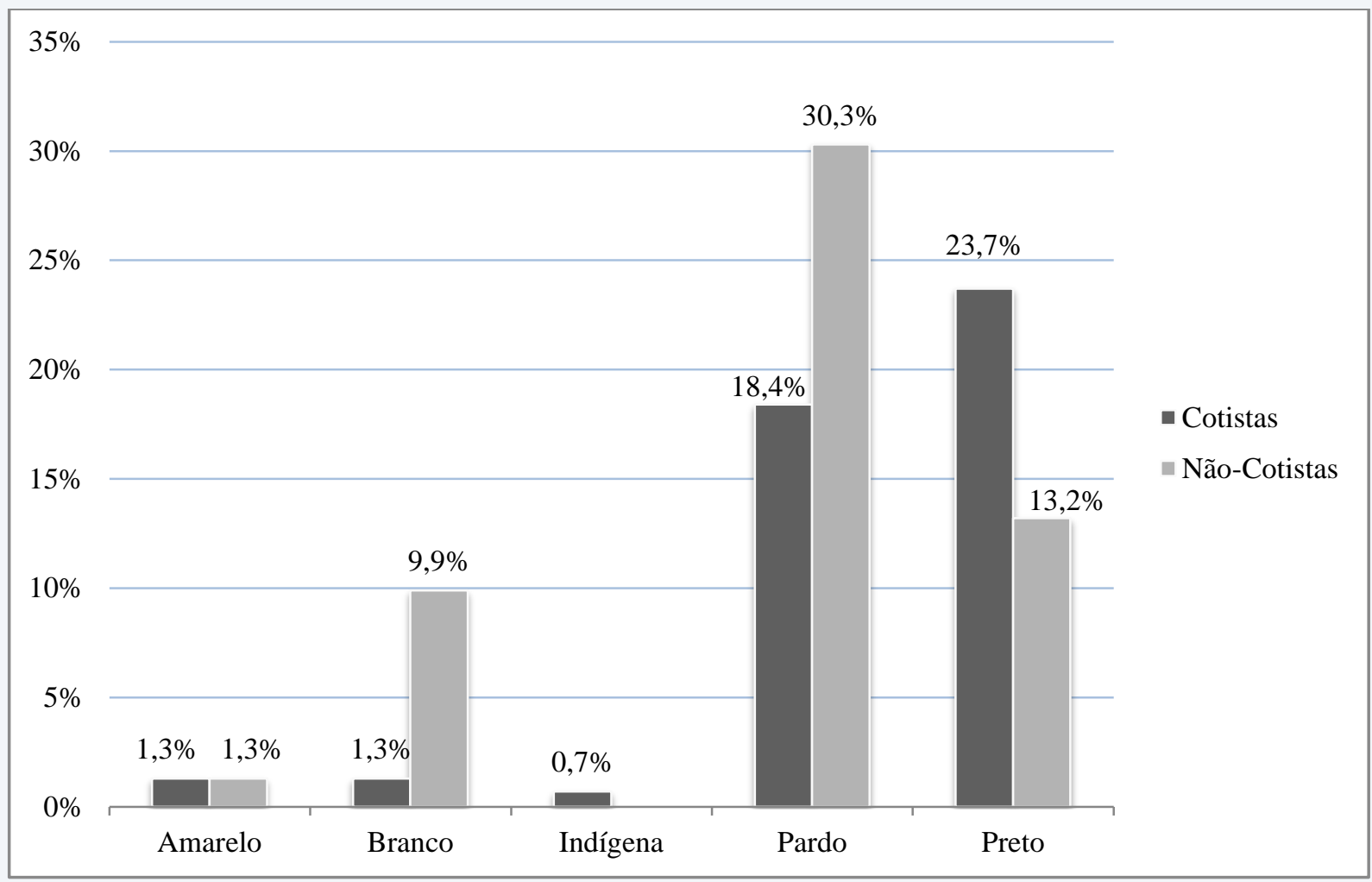

Fonte: Elaborado pelos autores a partir dos dados da UFBA.

A partir da observação da disposição das duas categorias estudantis (cotistas e nãocotistas) contrapostas à origem étnico-racial pôde-se perceber, também, que todos os estudantes indígenas, no período analisado, ingressaram no curso superior através da política de reserva de vagas da universidade.

Em comparação à renda familiar dos acadêmicos encontram-se algumas dessemelhanças. Os estudantes contemplados pelo sistema de cotas exibem, em maior concentração, uma renda familiar mensal na faixa de 01 (um) até 03 (três) salários mínimos (SM). Já os candidatos aprovados pela ampla concorrência expõem índices maiores na faixa de 03 (três) até 05 (cinco) salários mínimos. Percebe-se, no entanto, que no curso de Pedagogia da UFBA a diferença econômica dos discentes não apresenta extrema divergência, uma vez que ambas as categorias estudantis se encontram em faixas de renda bastante próximas. 
Gráfico 02: Relação Renda Familiar x Cotas.

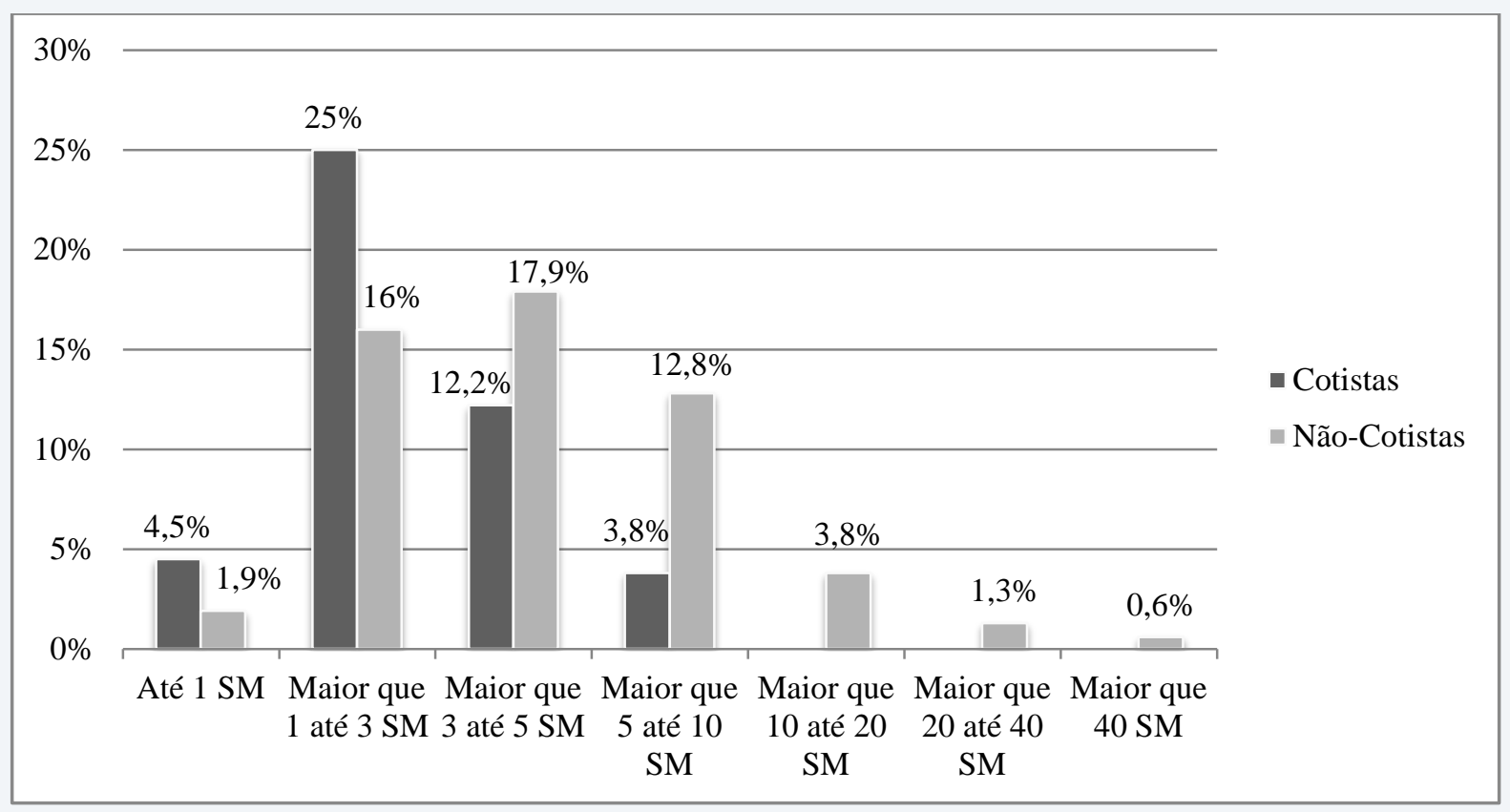

Fonte: Elaborado pelos autores a partir dos dados da UFBA.

A exploração do Gráfico 02 permite verificar uma realidade frequente nos cursos superiores. Nas primeiras categorias, onde encontram-se as menores rendas familiares mensais, os estudantes cotistas localizam-se em maior quantidade. Nas últimas categorias, que indicam rendas maiores, os não-cotistas prevalecem. No gráfico acima verificamos a ausência de estudantes cotistas com renda familiar acima de 10 (dez) SM. Além disso, é possível atestar que existem mais graduados da ampla concorrência com renda acima de 10 (dez) SM do que com a renda familiar de até 01 (um) SM.

Os estudos realizados por Lordêlo e Verhine (2001) apontam que os estudantes do curso de Pedagogia da UFBA apresentavam, de modo geral, uma renda familiar mensal de 05 (cinco) a 10 (dez) salários mínimos. Já os dados da presente pesquisa revelam que a maior parte dos discentes encontra-se na faixa de renda familiar de 01 (um) a 05 (cinco) salários mínimos mensais. Nesse sentido, percebe-se que houve uma modificação na variável renda ao longo do tempo, provavelmente derivada de políticas públicas como a expansão de vagas nos cursos superiores, o Sistema de Cotas, criação dos cursos noturnos, assistência estudantil, etc., que possibilitaram o aumento do ingresso de estudantes das camadas populares, implicando na alteração do perfil do alunado.

É importante destacar que a renda familiar dos acadêmicos é um forte indicador de análise visto que esta revela, muitas vezes, o prestígio social de determinado curso superior. 
Conforme estudo similar que realizamos ${ }^{3}$, no curso de Direito da UFBA, por exemplo, a distribuição da renda familiar ocorre da seguinte maneira: mais da metade dos estudantes (50,5\%), tanto cotistas quanto não-cotistas, encontram-se nas faixas acima de 10 salários mínimos mensais. Conforme nos alerta Santos (2012, p.8), o ensino superior brasileiro é pautado em uma lógica elitista e esta lógica pode ser confirmada quando verifica-se os cursos frequentados por sujeitos com alto poder aquisitivo em relação aos cursos frequentados por pessoas com extratos econômicos mais baixos.

Outro aspecto curioso encontrado na análise refere-se às condições estruturais de estudo. Dentre os estudantes cotistas, existem mais acadêmicos sem acesso à internet $(24,5 \%)$ do que com acesso $(20,6 \%)$. Além disso, no período da graduação, 20\% dos cotistas dividiam o tempo diário entre universidade e trabalho. Ambos os índices são maiores do que os apresentados pelos não-cotistas (Tabela 01). De acordo com Santos e Almeida Filho (2009, p. 229-230):

Mesmo sendo eficiente e inclusiva, a instituição dificilmente compensará o fato de que alguns alunos, vivendo em ambientes sofisticados e estimulantes, podem apenas estudar, contando ainda com recursos e suportes adicionais (por exemplo, contratando cursos complementares), enquanto outros continuarão lidando com problemas econômicos, vivendo precariamente, trabalhando em paralelo ao curso universitário, sem livros, equipamentos e recursos pessoais. Por esses motivos, defendo que devemos manter sistemas de compensação redistributiva de vagas (cotas para pobres, negros e índios), até que tenhamos verificado serem os mesmos desnecessários.

É sabido que estes aspectos são fatores que interferem diretamente no rendimento acadêmico dos estudantes já que a vida universitária exige uma série de hábitos regulares que são dificultadas com a presença do exercício de atividade remunerada e ausência do acesso à internet. Contudo, mesmo diante destes entraves, os cotistas, no curso de Pedagogia, conseguiram superar as discrepâncias introdutórias, exibindo as melhores notas ao término, conforme discutiremos adiante.

Em relação à escola de Ensino Médio frequentada pelos estudantes nota-se que os cotistas cursaram a última etapa da educação básica exclusivamente em escolas públicas $(45,2 \%)$, requisito essencial para o candidato ser considerado cotista, ao passo que os nãocotistas se dividem em escola pública $(21,3 \%)$ e escola particular $(33,5 \%)$. Ou seja, do total de universitários de Pedagogia 66,5\% são oriundos da escola média pública.

\footnotetext{
${ }^{3}$ No prelo.
} 
Gráfico 03: Relação Natureza da Escola Média x Cor ou Raça.

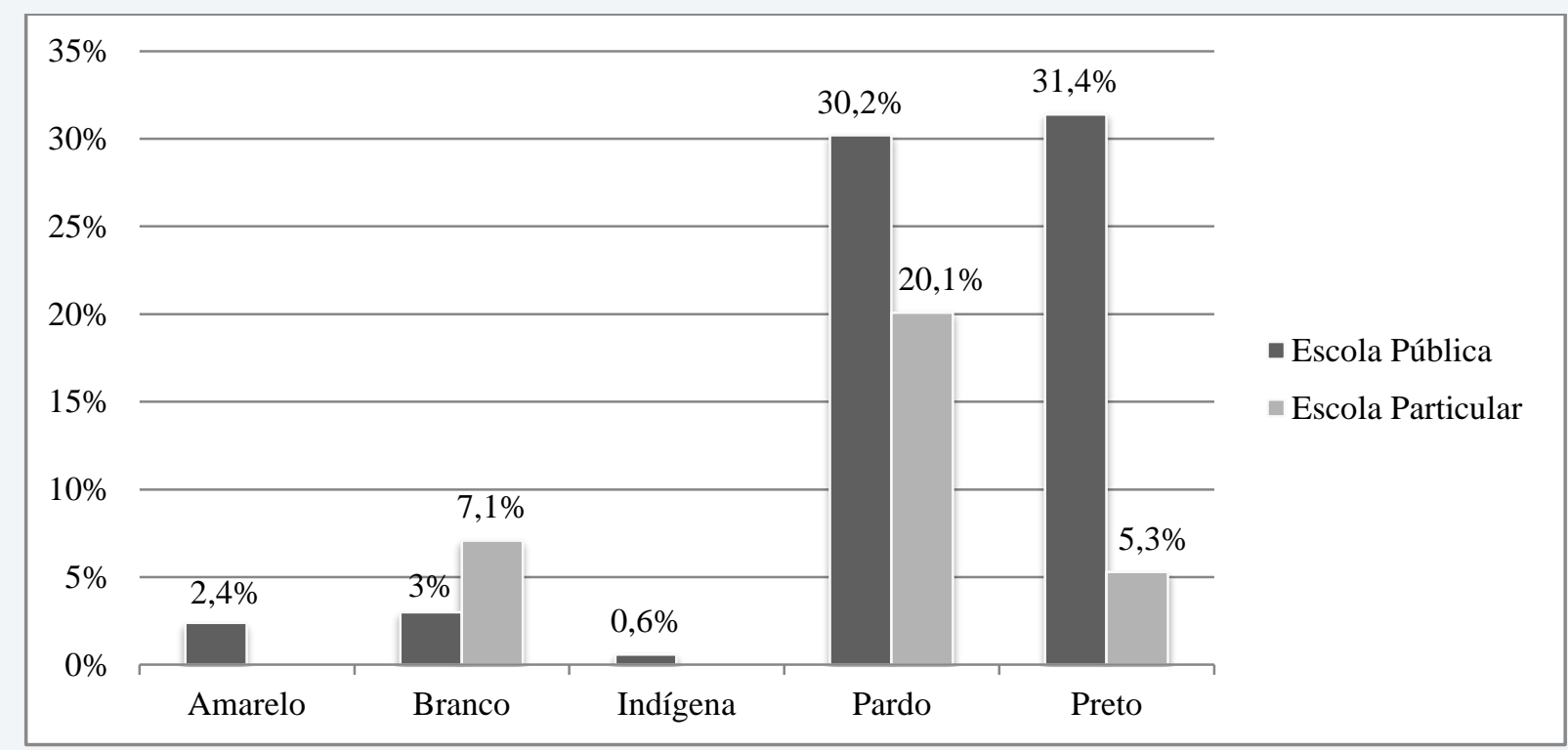

Fonte: Elaborado pelos autores a partir dos dados da UFBA.

A partir da correlação entre a natureza da escola média e origem étnico-racial do estudante, presente no Gráfico 03, é válido reconhecer que os alunos negros (pretos e pardos) são predominantemente egressos da escola pública. O número de pretos egressos da rede pública é 5,9 vezes maior do que da rede particular. Outro aspecto interessante observado concerne aos discentes amarelos e indígenas. Estes acadêmicos em nenhum registro presente no banco de dados, no período estudado, encontram-se nas instituições privadas. Em outras palavras, todos os amarelos e indígenas graduados entre 2005 e 2013 são oriundos da escola pública. Já os alunos brancos, embora sejam em menor quantidade do que os pretos, são provindos em maior número das escolas particulares de ensino médio. Assim, cerca de $30 \%$ dos brancos, $60 \%$ dos pardos e $85 \%$ dos pretos são oriundos da escola pública.

Os indicadores de desempenho acadêmico também foram relacionados à variável cota. Para melhor compreender o desempenho estudantil durante a graduação foram analisadas as notas dos alunos no vestibular (EscoreVest) e o coeficiente de rendimento final (CR). Observando o comportamento dos estudantes cotistas e não-cotistas de Pedagogia no processo seletivo para ingresso algumas disparidades já foram encontradas. Enquanto os cotistas demonstram no vestibular uma média de 12034,2, os não cotistas apresentam a média de 12070,7 .

Ainda que as discrepâncias no escore médio do vestibular dos universitários não se apresente de forma alarmante, os testes estatísticos realizados apontaram diferenças significativas nos rendimentos estudantis das duas categorias. Em vista disso, buscou-se 
verificar os índices de desempenho destes ao final da graduação a fim de perceber se a universidade tem dado condições para que essas desigualdades sejam superadas. Dessa forma, constatou-se que ao encerramento do curso superior os alunos cotistas exibem um rendimento acadêmico maior do que os não-cotistas. Na medida em que os assistidos pela política de reserva de vagas concluem o curso com um coeficiente de rendimento médio de 8,6, os demais acadêmicos terminam com a média de 8,5.

Tabela 02: Desempenho acadêmico dos cotistas e não-cotistas graduados em Pedagogia na UFBA no vestibular e coeficiente de rendimento. (2005-2013).

\begin{tabular}{lcccccc}
\hline & & Moda & Mediana & Média & $\begin{array}{c}\text { Desvio } \\
\text { Padrão }\end{array}$ & *P-valor \\
Cotistas & EscoreVest & 12621,2 & 11886,4 & 12034,2 & 535,01797 & $<0,007$ \\
& CR & 8,7 & 8,7 & 8,6 &, 5128 & $>0,679$ \\
Não-cotistas & EscoreVest & 11077,7 & 11870,7 & 12070,7 & 732,12771 & $<0,007$ \\
& CR & 8,7 & 8,7 & 8,5 &, 5748 & $>0,679$ \\
& & & & & & \\
\hline
\end{tabular}

*Significância estatística ao nível de 5\%.

Fonte: Elaborado pelos autores a partir dos dados da UFBA.

Baseado nas estatísticas descritivas acerca do desempenho acadêmico (Tabela 02) é permitido constatar alterações nas notas dos estudantes ao longo da graduação. Buscando entender com maior propriedade o que revelam as diferenças nos dados obtidos sobre o escore no vestibular e coeficiente de rendimento dos dois grupos estudantis foi realizado, no software IBM SPSS, o Teste de Amostras Independentes. Este apontou, a partir do p-valor <0,007, que no vestibular, cotistas e não-cotistas de Pedagogia, apresentam diferenças estatisticamente significativas. Em outras palavras, os estudantes cotistas ingressam ao curso de Pedagogia com notas consideravelmente menores do que os não-cotistas.

No entanto, ainda que os testes estatísticos e a média apresentem uma melhor pontuação no vestibular para os candidatos da ampla concorrência, ao analisar as demais medidas de tendência central o resultado é alterado. A mediana - que indica o valor que se encontra no meio da amostra - e a moda - que desvela os valores que mais se repetem dentro do conjunto total de cada categoria estudantil - apresentam os cotistas com um melhor desempenho quando comparado aos não-cotistas. Essas diferenças nas informações ocorrem devido a sensibilidade da média a valores extremos que, por vezes, pode ocultar a sequência apresentada no conjunto de dados analisados. Assim é interessante a análise dos resultados das demais medidas centrais na compreensão do desempenho estudantil no vestibular. 
A análise dos dados do Coeficiente de Rendimento (CR) apontou, a partir do p-valor $>0,679$, que ao completar o curso superior os estudantes cotistas e não-cotistas de Pedagogia da UFBA deixam de apresentar diferenças estatisticamente significativas. Ou seja, no final da graduação as duas categorias apresentam escores tão próximos que a origem escolar do estudante deixa de ter a mesma influência da entrada. Este aspecto indica que o sistema de reserva de vagas, nesse caso, evidenciou um resultado bastante positivo uma vez que as pessoas afastadas historicamente dos níveis mais elevados de educação formal, ao entrarem em contato com o ensino superior, exibem desempenhos acadêmicos equiparados.

Entendemos, assim como Santos (2009, p.66), que o aumento do acesso de estudantes negros nos cursos universitários caracteriza-se como o objetivo imediato das Políticas de Ações Afirmativas uma vez que assim se ampliaria a democratização do ensino superior. Entretanto compreendemos também a indispensabilidade de pesquisas científicas que investiguem os rendimentos acadêmicos deste novo grupo universitário para verificar os índices do percurso formativo. Desse modo, a origem étnico-racial e as notas dos estudantes foram cruzadas a fim de uma melhor apreensão da relação entre cor/raça e desempenho.

Tabela 03: Relação da Cor ou Raça x Desempenho Acadêmico x Cotas.

\begin{tabular}{c|c|c|c|c|c|c}
\hline \multicolumn{2}{|c|}{ Branco } & \multicolumn{2}{c|}{ Pardo } & \multicolumn{2}{c}{ Preto } \\
& Cotista & Não-Cotista & Cotista & Não-Cotista & Cotista & Não-Cotista \\
EscoreVest & 11393,7 & 12380,4 & 12111,0 & 11988,5 & 11989,9 & 12094,3 \\
CR & 7,9 & 8,3 & 8,7 & 8,5 & 8,6 & 8,5 \\
\hline
\end{tabular}

Fonte: Elaborado pelos autores a partir dos dados da UFBA.

Fundamentado nas informações encontradas na Tabela 03, podemos perceber uma distinção entre os desempenhos de brancos e negros (pretos e pardos). No vestibular, as menores notas médias encontradas referem-se aos estudantes cotistas de cor branca. Em seguida encontram-se os cotistas pretos e não-cotistas pardos. Uma singularidade identificada nesta análise diz respeito ao desempenho dos pardos: no processo de admissão ao curso superior, os estudantes cotistas, desta cor/raça, exibem rendimento superior aos candidatos da ampla concorrência.

Quanto à relação entre o coeficiente de rendimento e cor, os negros ingressos por meio da política de cotas são responsáveis pelas maiores notas médias. Os pardos cotistas exibem os maiores números, seguidos pelos pretos, com 8,7 e 8,6, respectivamente. Em seguida, 
pardos e pretos não-cotistas empatam com 8,5. Os candidatos brancos, não-cotistas e cotistas, revelam os menores desempenhos, 8,3 e 7,9, nesta ordem.

Posteriormente, as variáveis de desempenho, EscoreVest e CR, foram distribuídas em quintis. Neste modelo, as menores e maiores notas encontram-se no primeiro e último quintis, respectivamente. Dessa forma, foi possível compreender com maior detalhamento a disposição dos cotistas e não-cotistas nos rendimentos acadêmicos de entrada e saída da graduação. Assim sendo, pôde-se realizar uma investigação mais precisa permitido verificar a distribuição dos dois grupos universitários nas variáveis exploradas.

Gráfico 04: Relação Escore no Vestibular x Cotas.

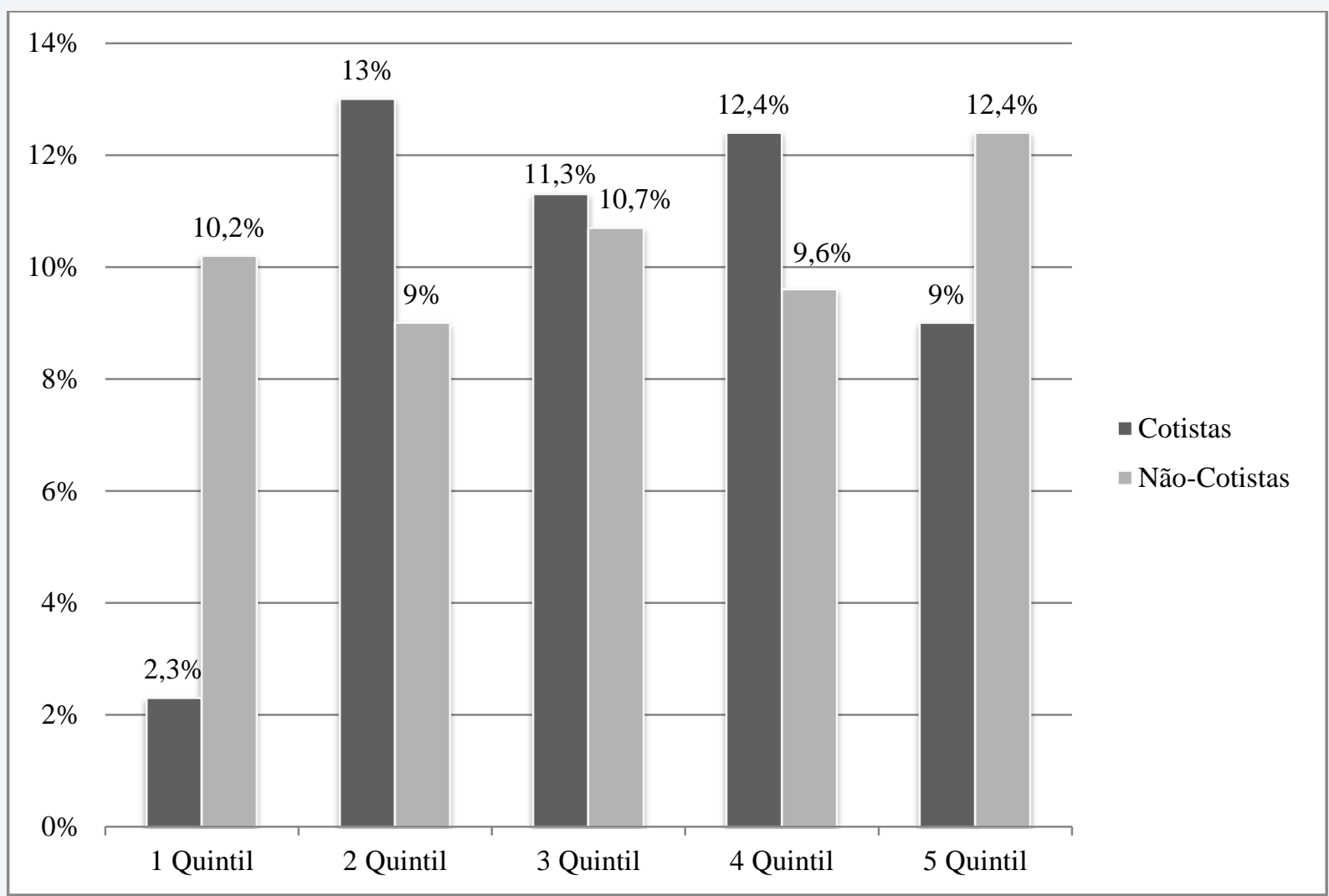

Fonte: Elaborado pelos autores a partir dos dados da UFBA.

Em conformidade ao Gráfico 04, que dispõe da distribuição dos estudantes em quintis com base nas notas no ingresso, identifica-se, curiosamente, que no primeiro quintil (notas mais baixas) encontram-se em maior número os estudantes não-cotistas. Contrariando os argumentos dos opositores à Política de Ações Afirmativas na UFBA, que alegavam a entrada de estudantes da escola pública como elemento prejudicial aos cursos superiores pois diminuiria as pontuações, no curso de Pedagogia se evidencia que não são os cotistas que apresentam as menores notas. 
No segundo (notas baixas), terceiro (notas médias), e quarto (notas altas) quintis, os cotistas predominam nos índices, apresentando heterogeneidades no desempenho do vestibular. O último quintil, que reserva as notas mais altas, é ocupado maioritariamente por estudantes não-cotistas.

Gráfico 05: Relação Coeficiente de Rendimento x Cotas.

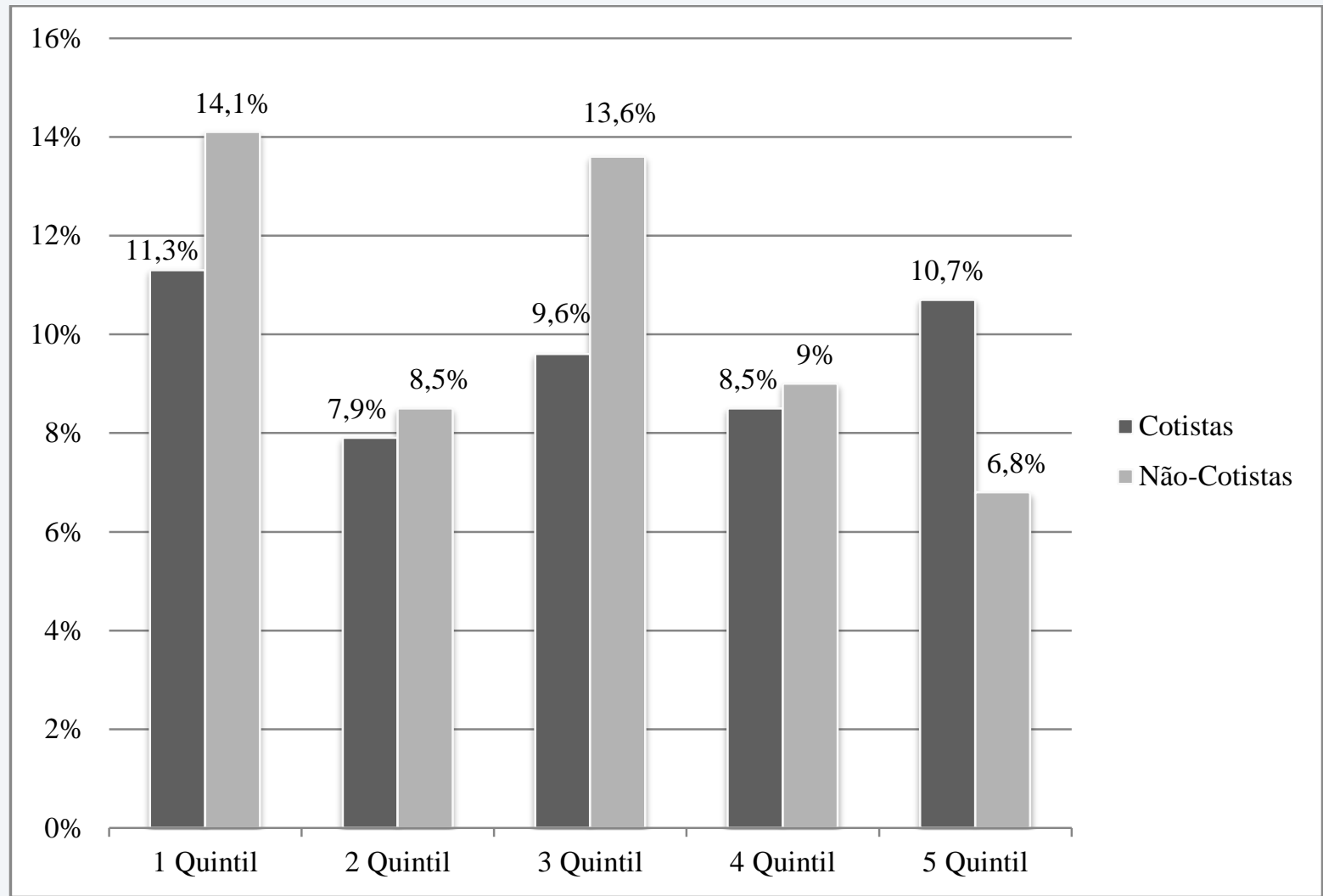

Fonte: Elaborado pelos autores a partir dos dados da UFBA.

A análise do Gráfico 05, que acomoda os resultados dos coeficientes de rendimentos dos estudantes ao fim do curso, permite verificar que os não-cotistas permanecem apresentando os escores mais baixos predominando, em termos numéricos, nos três primeiros quintis. O quarto quintil (notas altas) é bem disputado entre os dois grupos de universitários, e o quinto quintil (notas mais altas) é dominado pelos estudantes egressos do sistema de reserva de vagas.

Dessa forma, diante de todos os resultados obtidos através desta pesquisa, é legítimo afirmar que o curso de Licenciatura em Pedagogia da UFBA tem conseguido promover equidade no desempenho acadêmico dos seus discentes, já que as diferenças estatisticamente significativas no rendimento foram superadas ao final da graduação. Embora cotistas e não- 
cotistas apresentem perfis distintos, os seus rendimentos acadêmicos ao completar o ensino superior revelam-se bastante equiparados.

\section{CONSIDERAÇÕES FINAIS}

Diante dos resultados encontrados a partir das análises estatísticas acerca do perfil e desempenho acadêmico dos estudantes cotistas e não-cotistas de Pedagogia da UFBA é possível refletir sobre a Política de Cotas no combate às desigualdades. Os dados apresentados permitiram verificar que a exclusão do acesso ao ensino superior historicamente destinada às pessoas das camadas menos abastadas configura-se como estratégia de permanência de privilégios sócio-raciais dos segmentos dominantes, uma vez que os cotistas, pessoas que dificilmente conseguiriam ingresso a este nível de ensino senão pelo sistema de reserva de vagas, exibem rendimentos equivalentes aos acadêmicos da ampla concorrência.

Dessa forma é permitido atestar que o curso de Pedagogia da UFBA tem conseguido promover equidade no desempenho acadêmico dos estudantes, visto que as diferenças estatisticamente significativas encontradas no vestibular foram superadas quando estudadas as notas destes acadêmicos na saída do curso. Nesse sentido, como destacam Queiroz e Santos (2005-2006), com os resultados a respeito do desempenho acadêmico dos cotistas pode-se refutar a ideia de que os estudantes das camadas populares e/ou das escolas públicas, ingressos através do sistema de reserva de vagas, seriam responsáveis por desvalorizar ou diminuir a pontuação dos cursos superiores.

Compreendendo o curso de Pedagogia da UFBA como de pouco prestígio social, percebemos uma aproximação entre as características socioeconômicas das duas categorias estudantis analisadas. Dessa forma, entende-se a necessidade de estudos posteriores relativos ao desempenho estudantil dos contemplados pela reserva de vagas nos demais cursos superiores, sobretudo nos de maior admiração social, para apreender o comportamento dos cotistas em espaços de educação, ainda que públicos, elitizados.

\section{REFERÊNCIAS}

BRASIL. Lei $N^{\circ} 12.711$, de 29 de agosto de 2012. Dispõe sobre o ingresso nas universidades federais e nas instituições federais de ensino técnico de nível médio e dá outras providências. Disponível em Acesso em 16 out. 2012. 
DAFLON, Verônica Toste; FERES JÚNIOR, João; CAMPOS, Luiz Augusto. Ações afirmativas raciais no ensino superior público brasileiro: um panorama analítico. Cadernos de Pesquisa. v.43, n.148, p.302-327, jan. /abr. 2013.

DUBET, François. Qual democratização do ensino superior?. In: BARBOSA, M. L. O.

(Org.). Caderno CHR: revista do Centro de Estudos e Pesquisas em Humanidades da UFBA. Salvador, v.28, n.74, p. 255-265, Maio/Ago. 2015.

LORDÊLO, José Albertino Carvalho; VERHINE, Robert Evan. Perfil de Aluno e Rendimento Escolar em Pedagogia: Correlacionando variáveis na UFBA. Revista da FACED, 2001, p.57-70.

QUEIROZ, Delcele Mascarenhas. O Acesso ao Ensino Superior: gênero e raça. CADERNO CRH, Salvador, n. 34, p. 175-197, jan./jun. 2001.

QUEIROZ, Delcele Mascarenhas; SANTOS, Jocélio Teles dos. Vestibular com cotas: análise em uma instituição pública federal. REVISTA USP, São Paulo, n.68, p. 58-75, dezembro/fevereiro 2005-2006.

SANTOS, Boaventura de Sousa; ALMEIDA FILHO, Naomar. A Universidade do século XXI: para uma universidade nova. Coimbra: Almedina, 2008.

SANTOS, Dyane Brito Reis. Para além das cotas: a permanência de estudantes negros no ensino superior como política de ação afirmativa. Tese de Doutorado em Educação da Universidade Federal da Bahia, 2009. 214 p.

SANTOS, Manoel Gonçalves dos. Universidade contemporânea: Elitização e influência do ideário neoliberal. VI Colóquio Internacional Educação e Contemporaneidade. São Cristóvão - SE, Brasil, 2012.

\section{SOBRE OS AUTORES}

\section{Gabriel Swahili Sales de Almeida}

Doutor em Educação, UFBA; UFBA - Brasil; Membro do Grupo de Pesquisa Política e Gestão da Educação. E-mail: swahili@ufba.br

(iD) http://orcid.org/0000-0001-9801-2683

\section{Caio Vinícius dos Santos Silva}

Mestrando em Educação, UFBA; UFBA - Brasil; Programa de Pós-Graduação em Educação; Membro do Grupo de Pesquisa Política e Gestão da Educação. E-mail: caioviniciusz@hotmail.com

(iD http://orcid.org/0000-0003-3112-0235

Recebido em 22 de março de 2018

Aprovado em 11 de agosto de 2019

Publicado em: 17 de setembro de 2019 